\title{
Increasing Outreach: Non-Salmon Species in the Subarctic North Pacific
}

\author{
Oleg Ivanov ${ }^{1}$ and Aleksandr Zavolokin ${ }^{2}$ \\ ${ }^{1}$ Pacific Research Fisheries Center (TINRO-center) 4 Shevchenko Alley, Vladivostok, 690600, Russia \\ ${ }^{2}$ North Pacific Fisheries Commission (NPFC), 2 F Hakuyo-hall, Tokyo University of Marine Science and \\ Technology, 4-5-7 Konan, Minato-ku, Tokyo 108-8477, Japan
}

Keywords: North Pacific Fisheries Commission, Pacific saury, chub and spotted mackerels, Japanese sardine, neon and Japanese flying squids, North Pacific armorhead and splendid alfonsino

A multinational salmon survey in the North Pacific planned as a part of the International Year of the Salmon (IYS) initiative provides an opportunity to collect valuable data on non-salmon species in the Subarctic North Pacific. The North Pacific Fisheries Commission (NPFC) is considering taking part in the survey to obtain new data and improve knowledge on NPFC's species of interest. The goal of this study is to review the past pelagic surveys conducted in the North Pacific with the emphasis on the period from January to March and find out what can be expected from the participation of NPFC in the NPAFC IYS survey.

The study was mostly based on data from the Russian pelagic expeditions in the high seas of the western and central Pacific Ocean from 1969 to 2017. There were 150 pelagic surveys conducted entirely or partly in the high seas, beyond exclusive economic zones, in those years. For more details on materials and methods, you can refer to Shuntov and Bocharov (2005). In addition to the Russian surveys, available published information on non-salmon species caught in the Japanese trawl and gillnet surveys has been reviewed (Ueno et al. 1996; Ishida et al. 1998; Fukuwaka et al. 2006; Murakami et al. 2016).

During the Russian surveys, a total of 947 species of fish, squids, crustaceans and other marine species, which are formally under the NPFC mandate ${ }^{1}$, were caught in the high seas from 1969 to 2017 . These include eight priority species for the NPFC Scientific Committee: Pacific saury, chub and spotted mackerels, Japanese sardine, neon and Japanese flying squids, North Pacific armorhead and splendid alfonsino. The mackerels, Japanese sardine, and splendid alfonsino had the highest occurrence and were registered about 2500, 1700, and 1600 times, respectively.

From January to March, chub and spotted mackerels, Japanese sardine, and Japanese flying squid were the most abundant in the western North Pacific (Fig. 1). They all are straddling stocks, and their abundance in the EEZs is also high, although it is not shown as the study was focused on the NPFC Convention Area. Pacific saury and neon flying squid had wider distribution. They were abundant in both western and central parts of the North Pacific. Most catches of splendid alfonsino occurred in the Emperor Seamounts area, but some fish were registered in the western North Pacific. Armorhead were caught only once in the period from January to March.

Published information about non-salmon species from the past winter salmon surveys conducted by Japan is limited. According to the results from three Japanese surveys conducted in 1996, 1998, and 2006 (Ueno et al. 1996; Ishida et al. 1998; Fukuwaka et al. 2006), 17 fish species were found in these surveys in the North Pacific. The number of squid species caught was seven. There also were different species of Coelenterata and Appendicularia. In total, at least 26 species were caught during these surveys. However, apparently, the number of species is actually larger as not all of individuals caught were identified and consequently were recorded as one group. All these species are under the NPFC mandate and therefore this data is of potential value for the NPFC. In addition, Murakami et al (2016) reviewed Japanese trawl and gillnet surveys conducted in 1980-2014 and found out that North Pacific armorhead regularly occurred as bycatch.

Therefore, from the data collected during the Russian and Japanese winter salmon surveys, all priority species of NPFC were caught in the NPFC Convention Area in the past. List of species caught also includes a lot of other species of NPFC mandate which potentially can be used by NPFC in the future.

Potential outputs for NPFC from joining the project could include improved knowledge about distribution and migration of priority species, validation and adjustment of models (ecosystem, suitable habitats etc), new biological

\footnotetext{
${ }^{1}$ Fisheries resources covered by the NPFC are all fish, mollusks, crustaceans and other marine species caught by fishing vessels within the Convention Area, excluding: (i) sedentary species insofar as they are subject to the sovereign rights of coastal States; and indicator species of vulnerable marine ecosystems as listed in, or adopted pursuant to the NPFC Convention; (ii) catadromous species; (iii) marine mammals, marine reptiles and seabirds; and (iv) other marine species already covered by preexisting international fisheries management instruments within the area of competence of such instruments.
} 
information for priority and other species of fish and squids, and other data related to oceanography, fish diets, and zooplankton.
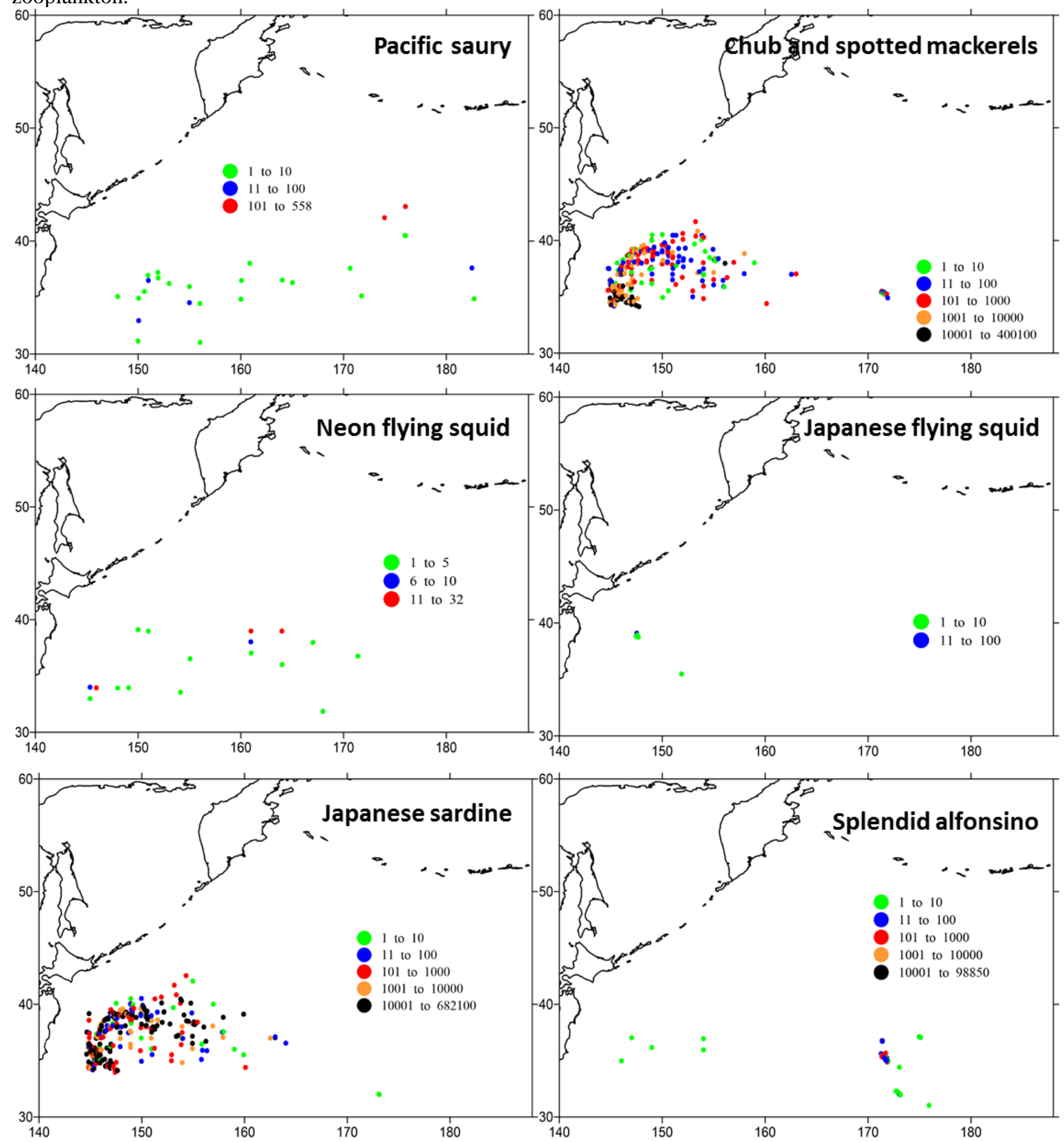

Fig. 1. Catch distribution of some NPFC priority species in the high seas of the North Pacific from January to March in 1969-2017, ind./hour of trawling

The IYS could benefit from cooperation with the NPFC through increased outreach and higher involvement of regional stakeholders, collaborative studies on marine ecosystems and modeling, development of integrated information systems and strengthened ties between NPAFC and NPFC. It could be of direct benefit to Canada, Korea, Japan, Russia, and the USA as they are members of both NPAFC and NPFC. 


\section{REFERENCES}

Fukuwaka, M., S. Sato, S. Takahashi, T. Onuma, N. Davis, J. Moss, A. Volkov, K.B. Seong, O. Sakai, N. Tanimata, and K. Makino. 2006. International salmon research aboard R/V Kaiyo maru in the North Pacific Ocean during the winter of 2006. N. Pac. Anadr. Fish Comm. Doc. 957. 12 pp. (Available at http://www.npafc.org)

Ishida, Y., Y. Veno, A. Shiomoto, T. Watanabe, T. Azumaya, M.V. Koval, and N.D. Davis. 1998. Japan-RussiaU.S. cooperative survey on overwintering salmonids in the western and central North Pacific Ocean and Bering Sea aboard R/V Kaiyo maru, 3 February-2 March, 1998. N. Pac. Anadr. Fish Comm. Doc. 329. 12 pp. (Available at http://www.npafc.org)

Murakami, C., S. Yonezaki, S. Suyama, M. Nakagami, T. Okuda, and M. Kiyota. 2016. Early epipelagic lifehistory characteristics of the North Pacific armorhead Pentaceros wheeleri. Fish Sci 82: 709-718.

Shuntov, V.P. and L.N. Bocharov (Editors). 2005. Atlas of nekton species quantitative distribution in the northwestern part of the Pacific Ocean. Moscow: «Natsionalnye rybnye resursy» Publishers, 2005. $1082 \mathrm{pp}$.

Ueno, Y., Y. Ishida, A. Shiomoto, S. Urawa, K.W. Myers, J. Morris, and M.V. Koval. 1996. Summary of wintering salmon research aboard R/V Kaiyo maru in January 1996. N. Pac. Anadr. Fish Comm. Doc. 213. 20 pp. (Available at http://www.npafc.org) 